\title{
The Extracellular cAMP-Adenosine Pathway in Airway Smooth Muscle
}

\author{
Enio S. A. Pacini, Sarah Sanders-Silveira, and Rosely O. Godinho \\ Division of Cellular Pharmacology, Department of Pharmacology, Escola Paulista de Medicina, Universidade Federal de São \\ Paulo (EPM/UNIFESP), São Paulo, Brazil
}

Received January 9, 2018; accepted April 16, 2018

\section{ABSTRACT}

In the respiratory tract, intracellular cAMP has a key role in the smooth muscle relaxation induced by the $\beta_{2}$-adrenoceptor/Gs protein/adenylyl cyclase axis. In other tissues, cAMP also works as an extracellular messenger, after its efflux and interstitial conversion to adenosine by ectoenzymes. The aim of this study was to identify cAMP efflux and the "extracellular cAMP-adenosine pathway" in the airway smooth muscle. First, we tested the ability of $\beta_{2}$-adrenoceptor agonists formoterol or fenoterol to increase the extracellular CAMP in isolated tracheal rings from adult male Wistar rats. The effects of adenosine, cAMP, 8-Br-cAMP, fenoterol, or formoterol were also evaluated in the isometric contraction of control or carbachol (CCh) precontracted tracheas, normalized as the percentage of $\mathrm{CCh}$-induced response. Fenoterol and formoterol induced $70 \%-80 \%$ relaxation and increased extracellular cAMP levels by up to $280 \%-450 \%$. Although exogenous cAMP or adenosine evoked phasic contractions, the membrane-permeable cAMP analog 8-Br-cAMP induced relaxation of CCh-precontracted tracheas. The simultaneous inhibition of adenosine degradation/uptake with EHNA [erythro9-(2-hydroxy-3-nonyl) adenine hydrochloride] plus uridine increased by 3 -fold the maximum CAMP-induced contraction, whereas it was significantly reduced by AMPCP [adenosine $5^{\prime}$ ( $\alpha, \beta$-methylene)diphosphate; an ecto-5'-nucleotidase inhibitor], and by adenosine receptor antagonists CGS-15943 (nonselective) or DPCPX (8-cyclopentyl-1,3-dipropylxanthine) ( $A_{1}$ selective). Finally, CGS-15943 shifted to the left the concentration-relaxation curve for fenoterol. In conclusion, our results show that airway smooth muscle expresses the extracellular cAMP-adenosine pathway associated with contracting effects mediated by $A_{1}$ receptors. The cAMP efflux triggered by fenoterol/formoterol indicates that the extracellular cAMP-adenosine pathway may play a role in balancing the relaxant effects of $\beta_{2}$-adrenoceptor agonists in airways, which may impact their bronchodilation effects.

\section{Introduction}

Adenosine is an endogenous purine nucleoside that works as a modulator of numerous cellular and molecular functions via activation of four adenosine receptor subtypes $\left(\mathrm{A}_{1}, \mathrm{~A}_{2 \mathrm{~A}}\right.$, $\mathrm{A}_{2 \mathrm{~B}}$, and $\mathrm{A}_{3}$ ) coupled to $\mathrm{G}$ protein. It is well established that ATP, a substrate for ectonucleotidases (CD39 and CD73), serves as important source of extracellular adenosine (Fredholm et al., 2011). However, since the middle 1990s, when the extracellular cAMP-adenosine pathway was first described in mammalian tissue (Mi and Jackson, 1995), a correlation between cAMP efflux through $\mathrm{ABCC}$ transporters and its degradation by ectoenzymes have been pointed to as an alternative source of extracellular adenosine (Mi and Jackson, 1995; Jackson and

This work was supported by Fundação de Amparo à Pesquisa do Estado de São Paulo (FAPESP, Grant 2015/07019-4, to R.O.G.) and Conselho Nacional de Desenvolvimento Científico e Tecnológico (CNPq; Grant 0309428/2015-7, to R.O.G.). E.S.A.P. is a Ph.D. fellow from CNPq and S.S.-S. is a Ph.D. fellow from Coordenação de Aperfeiçoamento de Pessoal de Nível Superior (CAPES), Brazil.

https://doi.org/10.1124/jpet.118.247734.
Raghvendra, 2004). This metabolic system has become a focus for an extracellular feedback mechanism that allows the control of physiologic responses triggered by the activation of adenylyl cyclases (ACs). In fact, several studies have reported the existence of the extracellular cAMP-adenosine pathway in mammalians cells, tissues, and organs (revised in Godinho et al., 2015). In this respect, previous findings from our laboratory have shown that the activation of the $\beta_{2}$-adrenoceptor/Gs protein/AC axis triggers the cAMP efflux from skeletal muscle cells (Godinho and Costa, 2003; Chiavegatti et al., 2008) that exert an extracellular negative-feedback effect on muscle contraction through adenosine formation and activation of postsynaptic $A_{1}$ receptors (Duarte et al., 2012).

Taking into account: 1 ) the central role of the $\beta_{2 \text {-adreno- }}$ ceptor/AC/cAMP signaling cascade in airway smooth muscle relaxation (Cazzola et al., 2012); 2) the autocrine or paracrine function of cAMP egress in skeletal, cardiac, and smooth muscles (Godinho and Costa, 2003; Cheng et al., 2010; Sassi et al., 2012); 3) the increased release of adenosine from airway cells during inflammatory processes associated to chronic lung disease (Huszár et al., 2002; Adriaensen and Timmermans,

ABBREVIATIONS: AC, adenylyl cyclase; AMPCP, adenosine 5'-( $\alpha, \beta$-methylene)diphosphate; 8-Br-cAMP, 8-bromo-cAMP; CCh, carbachol; CCh $\mathrm{EC}_{50}$, concentration of carbachol that produces $30 \%$ of the maximal response; CGS-15943, 9-chloro-2-(2-furanyl)-[1,2,4]triazolo[1,5-c]quinazolin5-amine; DMSO, dimethylsulfoxide; DPCPX, 8-cyclopentyl-1,3-dipropylxanthine; EHNA, erythro-9-(2-hydroxy-3-nonyl) adenine hydrochloride; $\mathrm{E}_{\max }$, maximal response; IBMX, 3-isobutyl-1-methylxanthine; PDE, phosphodiesterase; $\mathrm{pEC}_{50}, \mathrm{EC}_{50}$ value of potency; UNIFESP, Universidade Federal do São Paulo. 
2004); and 4) the growing evidence for adenosine involvement in bronchoconstriction in asthmatic patients (Wilson et al., 2009), we hypothesize that airway smooth muscle would exhibit cAMP efflux in response to $\beta_{2}$-adrenoceptor agonists and the extracellular cAMP-adenosine pathway, which could play a regulatory role in the airway smooth muscle contraction.

To test this idea, the effects of $\beta_{2 \text {-adrenoceptor agonists }}$ were evaluated on the extracellular cAMP level in an attempt to identify the efflux of cAMP from rat tracheal tissue. In addition, we also investigated the effect of exogenous cAMP on the isometric contraction of the rat isolated trachea under inhibition of 1) both adenosine deaminase and adenosine uptake, with EHNA [erythro-9-(2-hydroxy-3-nonyl) adenine hydrochloride] plus uridine; 2$)$ ecto- $5^{\prime}$-nucleotidase, with AMPCP [adenosine $5^{\prime}$-( $\alpha, \beta$-methylene)diphosphate]; and 3 ) adenosine receptors with the antagonists of adenosine receptors CGS-15943 [9-chloro-2-(2-furanyl)-[1,2,4]triazolo[1,5-c]quinazolin-5-amine] (nonselective) or DPCPX [8-cyclopentyl1,3-dipropylxanthine] ( $\mathrm{A}_{1}$ selective).

Our results showed that stimulation of airway smooth muscle with $\beta_{2}$-adrenoceptors formoterol and fenoterol induces tracheal smooth muscle relaxation, which is accompanied by cAMP efflux. Outside the tracheal cells, the cAMP is able to induce contracting effects mediated by the activation of $\mathrm{A}_{1}$ receptors. These results indicate that the extracellular cAMPadenosine pathway may play a role in balancing relaxant effects of $\beta_{2}$-adrenoceptor agonists in airway smooth muscle, which may affect the efficacy of these bronchodilators.

\section{Materials and Methods}

Animals and Ethical Approval. Adult male Wistar rats (3-4 months old; 250-350 g) were obtained from the Laboratory of Animal Experimentation of the National Institute of Pharmacology and Molecular Biology, Universidade Federal do São Paulo (UNIFESP; São Paulo, Brazil). All animals were maintained in pathogen-free environment under controlled conditions $\left(22 \pm 2{ }^{\circ} \mathrm{C}\right.$ and $50 \% \pm 15 \%$ relative humidity) in a 12 -hour light/dark cycle with free access to food and water. Rats were housed in clear polyethylene cages (four per cage) under standard laboratory conditions. The animal procedures and experimental protocols were approved by the Ethic Committee on Animal Use of the UNIFESP (protocol number 9987150714). Animal studies were performed in accordance with the Guide for the Care and Use of Laboratory Animals, as adopted and promulgated by the National Institutes of Health.

Isolated Tracheal Ring Preparation. Rats were killed by decapitation, and trachea, heart, and lungs were excised en bloc. The whole trachea was dissected and carefully cleaned from connective tissues. Two isolated tracheal segments containing four to five cartilaginous rings were obtained from the distal portion of the trachea (above the carina) (de Lima and da Silva, 1998) and immediately mounted in an isolated organ bath system (AVS Projetos, São Carlos, Brazil). The tracheal segments were positioned horizontally and suspended between stainless steel wire hooks in the organ bath containing salt buffer solutions at $37^{\circ} \mathrm{C}, \mathrm{pH} 7.4$, and continuously gassed with $95 \% \mathrm{O}_{2} / 5 \% \mathrm{CO}_{2}$. The lower hook was attached to a fixed holder at the bottom of the organ bath, and the upper hook was attached to an isometric force transducer (FT.03; Grass Technologies, West Warwick, RI) that was connected to a computer data acquisition system (PowerLab; ADInstruments, Bella Vista, NSW, Australia). The tracheal rings were gently stretched under a basal tension of $9.80 \mathrm{mN}$ and equilibrated for 1 hour before beginning the experiments.

Isometric Contraction Studies. After the equilibration period, the trachea segments were exposed to $1 \mu \mathrm{M}$ carbachol (CCh) for 2 minutes and washed several times with Krebs' solution, over a period of 30 minutes, to ensure muscle relaxation to a basal tension and the achievement of reproducible contractions. After 1 hour, the effects of drugs that interfere with the cAMP-adenosine pathway were investigated on tracheal contraction using two different experimental protocols: 1) the isolated tracheal rings under basal tension or 2) CCh-precontracted isolated tracheal rings. The isometric contractile forces were collected and analyzed using LabChart 7 software (ADInstruments-Australia). The Krebs' solution (5-ml organ bath) was employed in the contraction studies and consisted of the following: $119 \mathrm{mM} \mathrm{NaCl}, 4.7 \mathrm{mM} \mathrm{KCl}, 1.2 \mathrm{mM} \mathrm{MgSO}_{4}, 25 \mathrm{mM}$ $\mathrm{NaHCO}_{3}, 1.2 \mathrm{mM} \mathrm{KH}_{2} \mathrm{PO}_{4}, 2.5 \mathrm{mM} \mathrm{CaCl}_{2}$, and $11 \mathrm{mM}$ glucose, $\mathrm{pH}$ 7.4. The values of the contractile responses were normalized as percentages of the maximal response $\left(\mathrm{E}_{\max }\right)$ obtained with $1 \mu \mathrm{M} \mathrm{CCh}$. Relaxation responses were normalized as percentages of the response obtained with an $\mathrm{EC}_{30}$ of $\mathrm{CCh}$. Concentration-response curves were analyzed by nonlinear regression (GraphPad Prism 5; GraphPad Software, San Diego, CA) using the three-parameter logistic. The $\mathrm{EC}_{50}$ values of potency $\left(\mathrm{pEC}_{50}\right)$ and $\mathrm{E}_{\max }$ were obtained from concentration-response curves.

Effect of cAMP and Adenosine on Tracheal Rings Under Basal Tension. In the first experimental protocol, the tracheal rings were exposed to $1 \mu \mathrm{M} \mathrm{CCh}$, and the effects of $300 \mu \mathrm{M}$ cAMP or $100-300 \mu \mathrm{M}$ adenosine on the contractility of isolated rat tracheal rings were examined immediately after the stabilization of basal tension. In some experiments, the amplitude of contraction induced by cAMP was analyzed in tracheal rings pretreated for 60 minutes with AMPCP (100 $\mu \mathrm{M}$; inhibitor of ecto-5'-nucleotidase), CGS-15943 (20 $\mu \mathrm{M}$; a nonselective adenosine receptor antagonist), a cocktail containing EHNA (10 $\mu \mathrm{M}$; inhibitor of adenosine deaminase), and uridine ( $50 \mu \mathrm{M}$; inhibitor of adenosine uptake), or their respective vehicles.

Effect of cAMP, Adenosine, and $\beta_{2}$-Agonist on Tracheal Rings Precontracted with CCh. In a group of experiments, after the stabilization of basal tension, a cumulative concentration-response curve to $\mathrm{CCh}$ was obtained to find the concentration of $\mathrm{CCh}$ that produces $30 \%$ of the $\mathrm{E}_{\max }\left(\mathrm{CCh} \mathrm{EC}_{30}\right)$. Thereafter, the tracheas were stimulated with the $\mathrm{CCh} \mathrm{EC}_{30}$ and contractile responses were recorded for 10 minutes. After a 1-hour washout out of the agonist and restoration of the basal tension, the tracheas were precontracted again with the $\mathrm{CCh} \mathrm{EC}_{30}$ for 10 minutes and incubated with formoterol (1 $\mu \mathrm{M}$; long-acting $\beta_{2}$-agonist), fenoterol ( $1 \mu \mathrm{M}$; short-acting $\beta_{2}$-agonist), 8-Br-cAMP (100 $\mu \mathrm{M}$; cell membrane-permeable cAMP analog), and compared with those of $300 \mu \mathrm{M}$ cAMP.

In another set of experiments, tracheal segments precontracted with $\mathrm{CCh} \mathrm{EC}_{30}$ were incubated with increasing noncumulative concentrations of adenosine $(1-1000 \mu \mathrm{M})$ or cAMP $(1-1000 \mu \mathrm{M})$ in the presence or absence of EHNA $(10 \mu \mathrm{M})$ plus uridine $(50 \mu \mathrm{M})$. In a further sequence of experiments, the influence of $100 \mu \mathrm{M}$ AMPCP, $2 \mu \mathrm{M}$ CGS-15943, or $100 \mu \mathrm{M}$ DPCPX was evaluated on the cAMPinduced contraction of tracheal rings precontracted with $\mathrm{CCh}$. Inhibitors and competitive antagonists were added to the organ bath 60 minutes before cAMP incubation.

Effect of Nonselective Adenosine Receptor Antagonist on Fenoterol-Induced Relaxation of CCh-Precontracted Tracheal Rings. Tracheal preparations were precontracted with $\mathrm{CCh}$ $\mathrm{EC}_{30}$ for 10 minutes, and then the first cumulative concentrationresponse curve to fenoterol was constructed by adding increasing concentrations of the agonist $\left(10^{-9}\right.$ to $\left.10^{-4} \mathrm{M}\right)$. After a 10 -minute washout period, the tissues were incubated with $2 \mu \mathrm{M}$ CGS-15943 or vehicle [dimethylsulfoxide (DMSO) $0.2 \%$ ] for 60 minutes and precon-

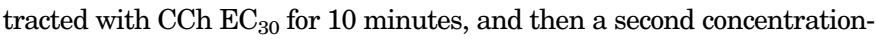
response curve to fenoterol was obtained. Finally, after washing and precontraction of the tracheal rings with $\mathrm{CCh} \mathrm{EC}_{30}$ for 10 minutes, a third concentration-response curve for fenoterol was obtained in the presence of $20 \mu \mathrm{M}$ CGS-15943 or vehicle (DMSO $0.2 \%$ ) previously incubated for 60 minutes.

Measurement of Extracellular cAMP. The experiments were performed using Tyrode's solution ( $135 \mathrm{mM} \mathrm{NaCl}, 5 \mathrm{mM} \mathrm{KCl}, 1 \mathrm{mM}$ $\mathrm{MgCl}_{2}, 15 \mathrm{mM} \mathrm{NaHCO}_{3}, 1 \mathrm{mM} \mathrm{NaH} \mathrm{PO}_{4}, 2 \mathrm{mM} \mathrm{CaCl}_{2}$, and $11 \mathrm{mM}$ 
glucose, $\mathrm{pH}$ 7.4), which has been stablished as the standard buffer solution for the determination of cAMP content in skeletal and smooth muscles in our laboratory. After a 1-hour equilibration period in an organ bath containing Tyrode's solution, the tracheal rings were incubated with $1 \mathrm{mM}$ IBMX [3-isobutyl-1-methylxanthine; nonselective inhibitor of intracellular and extracellular phosphodiesterase (PDE)] for 30 minutes to inhibit intracellular and extracellular degradation of cAMP, and then stimulated with $1 \mu \mathrm{M}$ formoterol or $1 \mu \mathrm{M}$ fenoterol. The incubation medium was collected at $0,10,30$, and 60 minutes after agonist treatment; transferred into microtubes containing ice-cold EDTA (4 mM final concentration); and immediately boiled in a dry bath for 15 minutes to denaturate PDEs and prevent cAMP hydrolysis. The samples were centrifuged at $10,000 \mathrm{~g}$ for 15 minutes at $4^{\circ} \mathrm{C}$ (Chiavegatti et al., 2008) and determination of cAMP levels from supernatants were performed using the Lance Ultra cAMP Kit (PerkinElmer, Waltham, MA) according to the manufacturer instructions in 96-well half-area microplates (PerkinElmer). The time-resolved fluorescence resonance energy transfer signal was measured using Flex Station 3 (Molecular Devices, San Jose, CA) with excitation at $340 \mathrm{~nm}$ and emission at 615 and $665 \mathrm{~nm}$, after a delay time of 50 microseconds and an integration time of 100 microseconds. The levels of extracellular cAMP were expressed as picomoles per tissue mass (picomole per milligram).

Data and Statistical Analysis. The data obeyed the normal distribution [i.e., they have passed the Kolmogorov-Smirnov test under the significant level of $\alpha=0.05$ and were presented as the mean \pm S.E.M. and experimental number $(n)$ represents the number of trachea segments obtained from different rats. Statistical analyses were performed using GraphPad Prism software (version 5.01; GraphPad Software). Differences between groups were determined by Student's $t$ test or one-way ANOVA followed by Dunnett's multiplecomparison test, and considered significant at $P<0.05$.

Materials. 8-Bromo-cAMP sodium salt, EHNA hydrochloride, and formoterol hemifumarate were purchased from Tocris Bioscience (Ellisville, MO). Adenosine, CCh, cAMP, CGS-15943, DPCPX fenoterol hydrobromide, uridine, AMPCP, and all other chemicals were purchased from Sigma-Aldrich (St. Louis, MO).

\section{Results}

$\beta_{2}$-Adrenoceptor Agonists Induce Relaxation of Tracheal Smooth Muscle and Stimulate Extracellular cAMP Accumulation. We have first investigated whether relaxation induced by activation of rat tracheal $\beta_{2}$-adrenoceptors could be followed by cAMP efflux. As shown in Fig. 1A, $\beta_{2}$-adrenoceptor agonists fenoterol ( $1 \mu \mathrm{M}$, short-acting) and formoterol (1 $\mu \mathrm{M}$, long-acting) relaxed CCh-precontracted tracheas by $79 \%$ and $69 \%$, respectively. The relaxing effects of these $\beta_{2}$-adrenoceptor agonists last for at least 30 minutes (data not shown) and were accompanied by a gradual increase in extracellular cAMP levels that reached $553 \%$ and $383 \%$ of the basal values (time zero: fenoterol $=1.52 \pm 0.24 \mathrm{pmol} / \mathrm{mg}$ tissue; formoterol $=1.83 \pm 0.42 \mathrm{pmol} / \mathrm{mg}$ tissue), after 60 minutes of stimulation (Fig. 1B). A discrete but significant increase (75\%) in extracellular cAMP was also found in control tracheas treated for 60 minutes with vehicle (time zero: vehicle $=1.59 \pm 0.30 \mathrm{pmol} / \mathrm{mg}$ tissue) (Fig. $1 \mathrm{~B}$ ), indicating that a basal cAMP efflux occurs even in the absence of $\beta_{2}$-adrenoceptor activation.

Extracellular cAMP Induces Contraction of Rat Precontracted Trachea via Activation of $A_{1}$ Adenosine Receptors by Its Metabolite Adenosine. To examine the possible functional relevance of extracellular cAMP on the airway smooth muscle contraction, we compared the effect of the exogenous $3^{\prime}, 5^{\prime}$-cAMP, which is unable to enter the cell
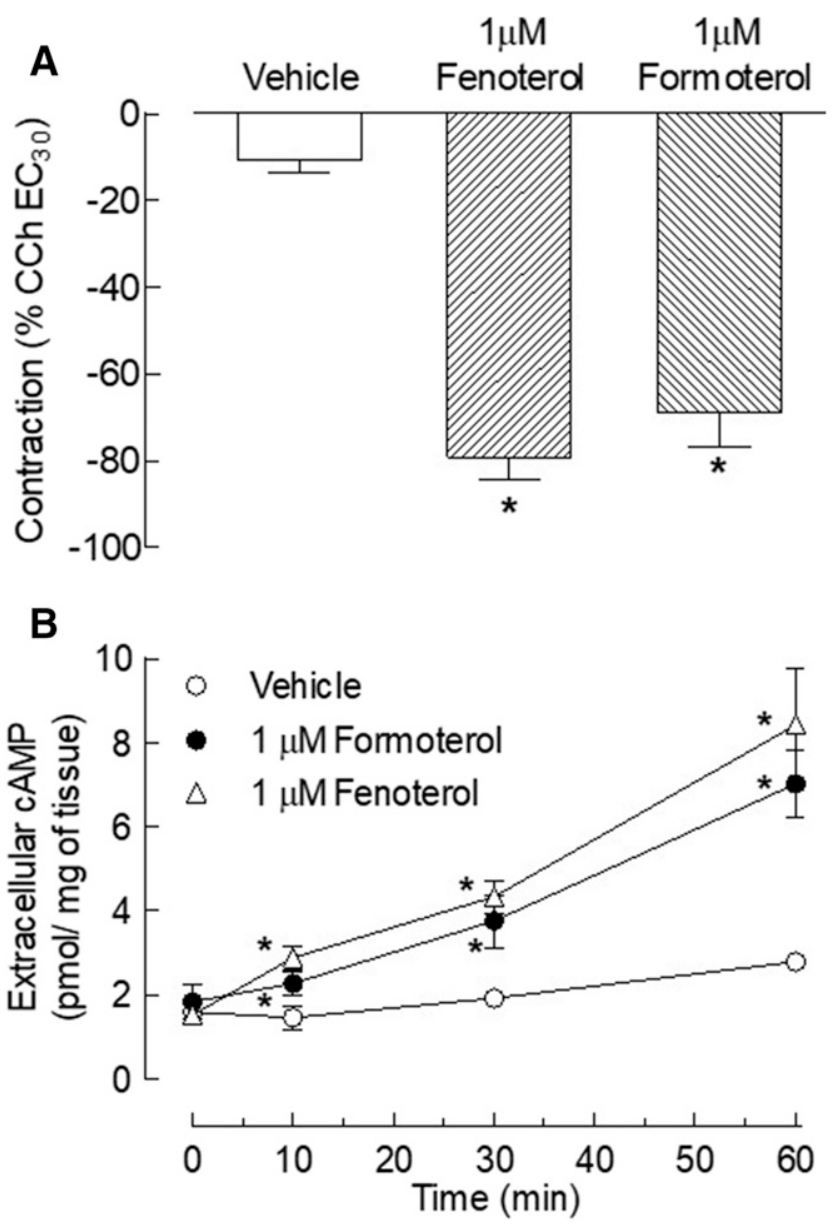

Fig. 1. The relaxing effects of $\beta_{2}$-adrenoceptor agonists in rat tracheal rings are followed by the increment in extracellular cAMP levels. (A) Maximum relaxation induced by $1 \mu \mathrm{M}$ formoterol or $1 \mu \mathrm{M}$ fenoterol in rat tracheal rings precontracted with $\mathrm{CCh} \mathrm{EC}_{30}(n=5-8)$. (B) The time course of extracellular cAMP accumulation in isolated tracheal rings exposed to $1 \mu \mathrm{M}$ formoterol or $1 \mu \mathrm{M}$ fenoterol or vehicle ( $n=5$ to 6 ) in the presence of $1 \mathrm{mM}$ IBMX. Data are presented as the mean \pm S.E.M. *Significantly different from control group (Vehicle) $(P<0.05$; Student's $t$ test).

(Robison et al., 1965), with that of 8-Br-cAMP, a cell membranepermeable cAMP analog that is resistant to intracellular and extracellular PDEs. As shown in Fig. 2, although $300 \mu \mathrm{M}$ cAMP caused the contraction of tracheal smooth muscle (Fig. 2, A and $\mathrm{C})$, the 8-Br-cAMP relaxed the $\mathrm{CCh}$-precontracted tracheal rings by $43 \%$ (Fig. 2 , B and C).

The contracting effect of cAMP was mimicked by adenosine (Fig. 3). However, the amplitudes of contractile responses induced by either cAMP (Fig. 3A) or adenosine (Fig. 3B) in CCh-precontracted tracheal rings were $\sim 2.5$-fold greater than those under basal conditions.

In fact, the incubation of CCh-precontracted tracheal rings with increasing concentrations of cAMP $(3-1000 \mu \mathrm{M})$ elicited phasic contractions in a concentration-dependent manner (Fig. 4, A and B). A similar effect was observed with adenosine $(1-1000 \mu \mathrm{M})$ (Fig. 4, C and D). However, the $\mathrm{pEC}_{50}$ of adenosine, obtained from the analysis of noncumulative concentration-response curves, was 11-fold greater than that of cAMP (Fig. 4G; Table 1). In addition, the $\mathrm{E}_{\max }$ for adenosine was significantly higher than that seen for cAMP (Table 1).

To evaluate the contribution of the metabolite adenosine to the contractile effect of extracellular cAMP in the rat tracheal 

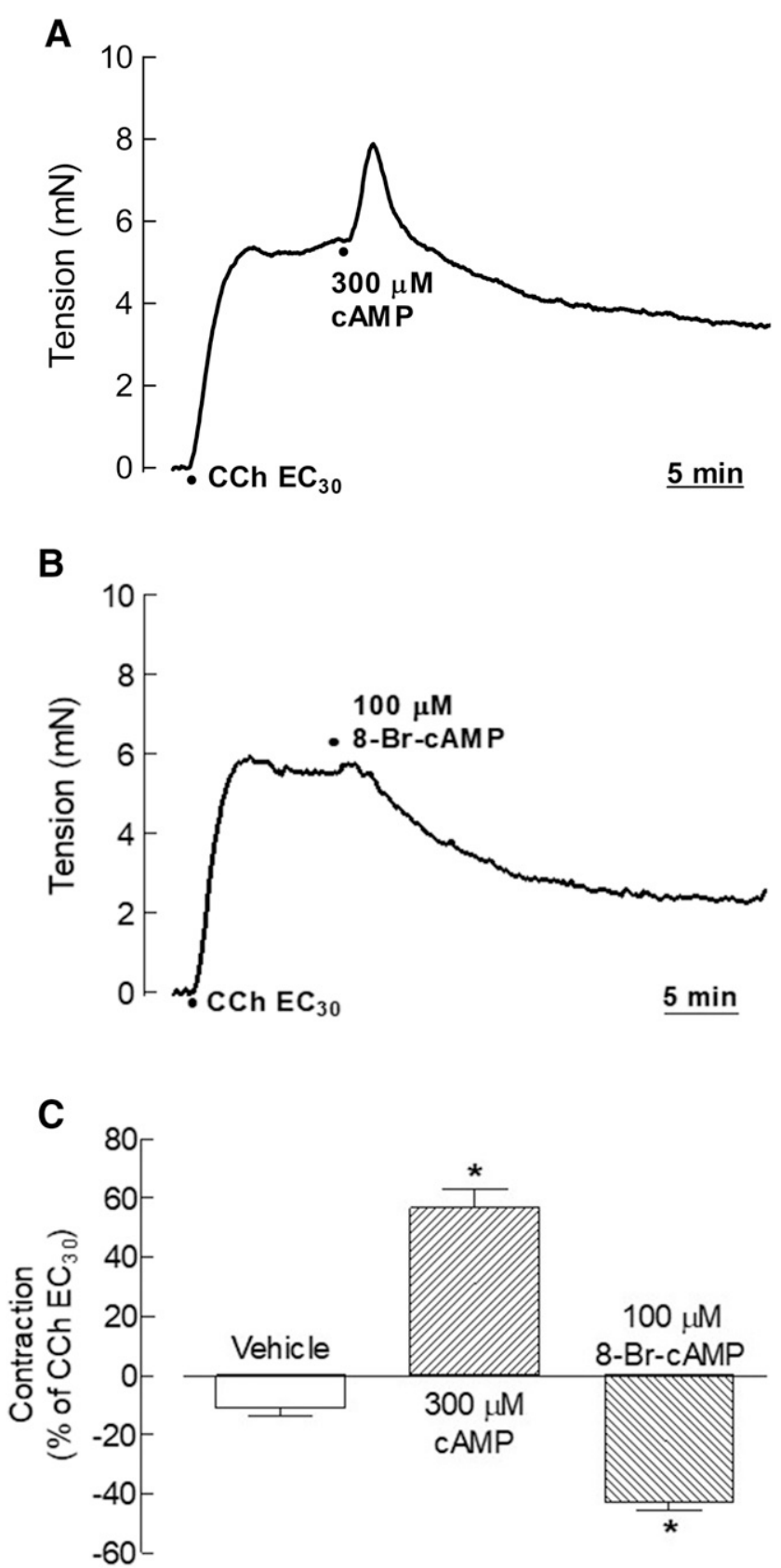

Fig. 2. cAMP and 8-Br-cAMP induce opposite inotropic effects in rat tracheal rings precontracted with $\mathrm{CCh} \mathrm{EC}_{30}$. Representative records of isometric contractions induced by $300 \mu \mathrm{M}$ cAMP (cell membrane-nonpermeable cyclic nucleotide) (A) and $100 \mu \mathrm{M}$ 8-Br-cAMP (cell membranepermeable cAMP analog) (B). (C) Data are presented as the mean \pm S.E. $\mathrm{M}$. and normalized as the percentage of the response induced by $\mathrm{CCh}^{\mathrm{E}} \mathrm{C}_{30}$ $(n=5-10)$. *Significantly different from control group (Vehicle) $(P<0.05$; Student's $t$ test).

rings, we inhibited the adenosine deaminase and adenosine uptake with a cocktail containing EHNA and uridine. In these conditions, cAMP elicited concentration-dependent phasic contractions (Fig. 4, $\mathrm{E}$ and $\mathrm{F}$ ) with an $\mathrm{E}_{\max }$ value $\sim 3$-fold higher than that in the absence of the cocktail inhibitors (Fig. 4G; Table 1). No significant change in the potency of cAMP was observed in the presence of EHNA and uridine (Fig. 4G; Table 1). Representative records of isometric contraction elicited by $300 \mu \mathrm{M}$ cAMP, $300 \mu \mathrm{M}$ adenosine, or

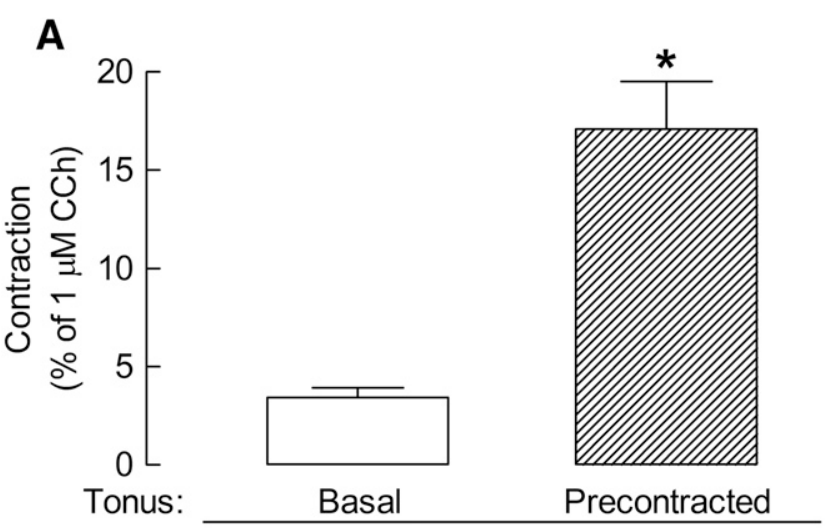

$300 \mu \mathrm{M}$ cAMP

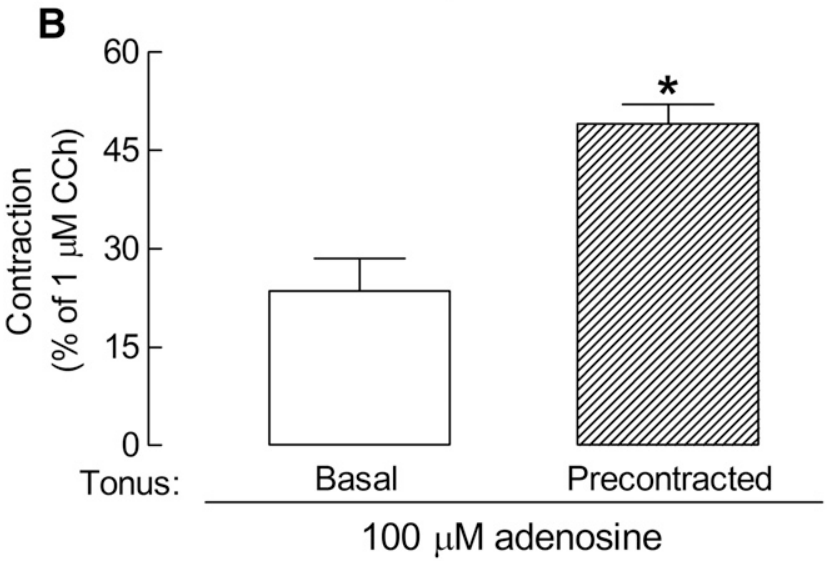

Fig. 3. Adenosine mimics the positive inotropic effect of cAMP in resting and precontracted rat tracheal rings. Maximum contraction induced by $300 \mu \mathrm{M}$ cAMP ( $n=10$ to 11 ) (A) or $100 \mu \mathrm{M}$ adenosine ( $n=5$ to 6$)(\mathrm{B})$ in rat tracheal rings under basal tonus (white bar) or precontracted with $\mathrm{CCh}$ $\mathrm{EC}_{30}$ (dashed bar). Data are presented as the mean \pm S.E.M. and normalized as the percentage of the response induced by $1 \mu \mathrm{M} \mathrm{CCh}$. *Significantly different from tracheal rings under basal tonus $(P<0.05$; Student's $t$ test).

EHNA/uridine plus $300 \mu \mathrm{M}$ cAMP in CCh-precontracted tracheal rings are shown in Fig. 4, B, D, and F.

Finally, we investigated the involvement of ecto-5'-nucleotidase and adenosine receptor in the contractile response elicited by extracellular cAMP. For these experiments, rat tracheal rings were preincubated for 60 minutes with $100 \mu \mathrm{M}$ AMPCP (an inhibitor of ecto-5'-nucleotidases), $2 \mu$ M CGS-15943 (a nonselective adenosine receptor antagonist), or $100 \mathrm{nM}$ DPCPX (a selective $A_{1}$ adenosine receptor antagonist) before the addition of $300 \mu \mathrm{M}$ cAMP. As seen in Fig. 5A, preincubation of the tracheas with AMPCP reduced by $57 \%$ the cAMPinduced contraction. Likewise, preincubation of tracheas with CGS-15943 or DPCPX reduced the contraction induced by cAMP by $63 \%$ and $54 \%$ (Fig. $5, \mathrm{~B}$ and C).

Extracellular cAMP Induces Contraction of Rat Trachea under Basal Tonus. As observed in precontracted trachea segments, under basal tonus the amplitude of contraction induced by adenosine $300 \mu \mathrm{M}$ was higher than that observed with the same concentration of cAMP (Fig. 6A). Pretreatment of smooth muscle preparation with EHNA/ uridine increased the contractile effect of $300 \mu \mathrm{M}$ cAMP by 2-fold (Fig. 6B). Finally, cAMP-induced contraction was almost completely abolished by preincubation of tracheal preparation either with the ecto-5'-nucleotidase inhibitor 

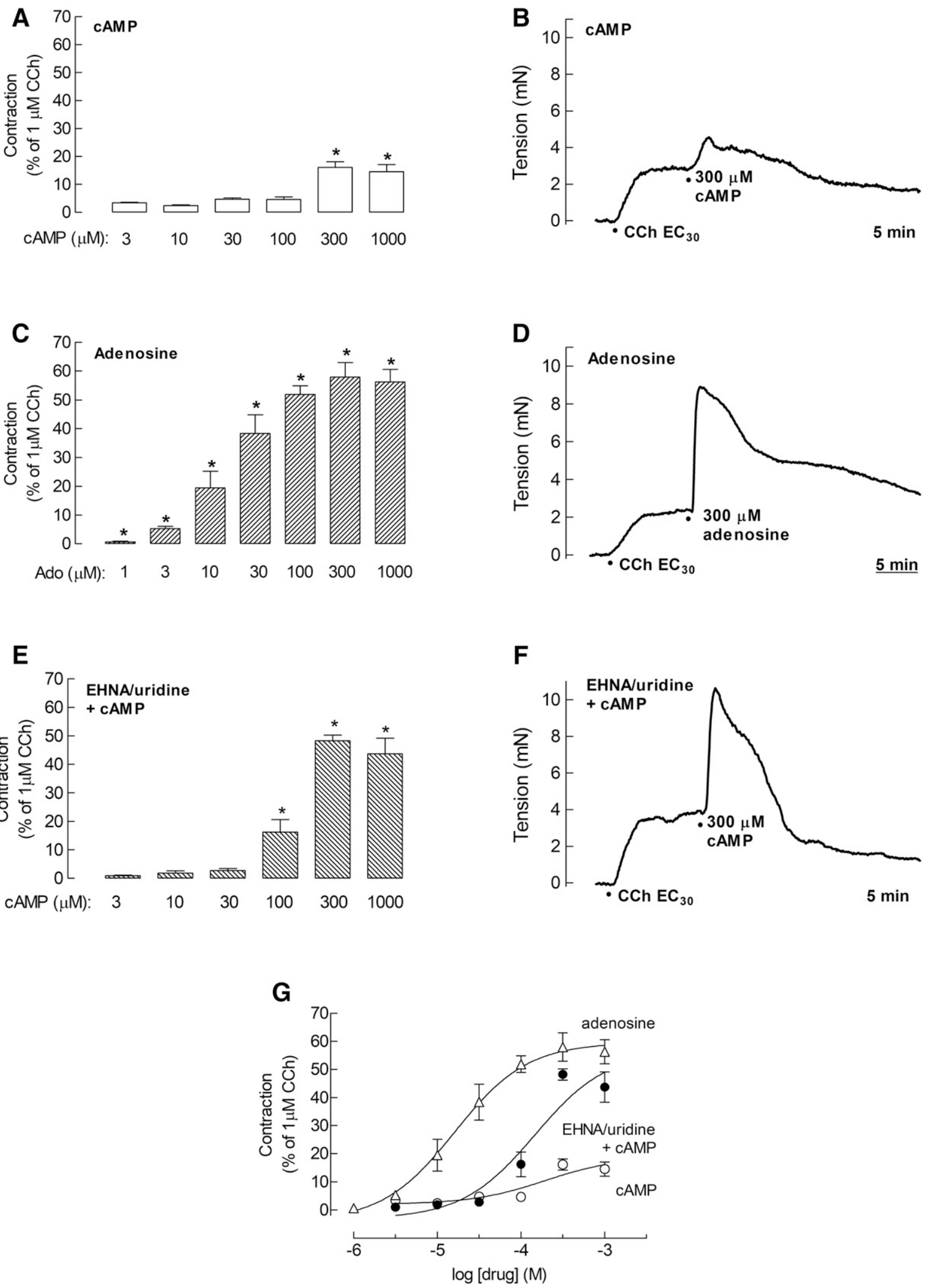

Fig. 4. Simultaneous inhibition of adenosine deaminase and adenosine uptake increases the contracting effect of cAMP. The isolated rat tracheas were contracted with $\mathrm{CCh} \mathrm{EC}_{30}$ for 10 minutes, and contractile responses induced by noncumulative addition of cAMP $(n=5-20)(\mathrm{A})$, adenosine $(n=5-8)(\mathrm{C})$, or cAMP plus EHNA and uridine $(n=5-7)(\mathrm{E})$ were observed. Representative records of isometric contractions induced by $300 \mu \mathrm{M}$ cAMP (B), $300 \mu \mathrm{M}$ adenosine (D), and $300 \mu \mathrm{M}$ cAMP plus EHNA and uridine (F). (G) Concentration-response curves derived for each drug in precontracted rat trachea. Data are presented as the mean \pm S.E.M. *Significantly different from contraction induced by $1 \mu \mathrm{M}$ CCh $(P<0.05$; ANOVA followed by Dunnett's multiple comparison test). 


\section{TABLE 1}

Values of $\mathrm{pEC}_{50}$ and $\mathrm{E}_{\max }$ for cAMP, adenosine, and cAMP plus EHNA and uridine obtained in rat tracheal rings precontracted with $\mathrm{CCh} \mathrm{EC}_{30}$

A noncumulative concentration-response curve for cAMP, adenosine, and cAMP plus EHNA and uridine were constructed from data demonstrated in Fig. 4 and analyzed through a nonlinear regression with GraphPad Prism 5 Software. Values are presented as the mean \pm S.E.M. $(n=5-20)$.

\begin{tabular}{lccc}
\hline & cAMP & Adenosine & cAMP + EHNA + Uridine \\
\hline $\mathrm{E}_{\max }(\%)$ & $18.76 \pm 566$ & $59.58 \pm 1.27^{*}$ & $56.64 \pm 12.80^{*}$ \\
$\mathrm{pEC}_{50}$ & $3.71 \pm 0.51$ & $4.79 \pm 0.06^{*}$ & $3.83 \pm 0.36$
\end{tabular}

*Significantly different from cAMP $(P<0.05$; Student's $t$ test $)$

AMPCP (Fig. 6C) or with the nonselective adenosine receptor antagonist CGS-15943 (Fig. 6D).

Nonselective Adenosine Receptor Antagonist Potentiates the Relaxation Response Induced by $\beta_{2}$-Adrenergic Receptor Agonist. To evaluate the reproducibility of the cumulative concentration response to fenoterol in the same tracheal preparations, we initially constructed three consecutive concentration-response curves to fenoterol at intervals of 60 minutes. As shown in Fig. 7A, the first concentrationresponse curves to fenoterol presented a mean $\mathrm{pEC}_{50}$ of $7.03 \pm 0.18(n=4)$. However, second and third concentrationresponse curves to fenoterol produced a 5 -fold $\left(\mathrm{pEC}_{50}\right.$ second curve $=6.36 \pm 0.10 ; n=4)$ and an 11-fold rightward shift $\left(\mathrm{pEC}_{50}\right.$ third curve $=5.99 \pm 0.13 ; n=4)$, respectively. The reduction in fenoterol potency observed after consecutive concentrationresponse curves forced us to evaluate the effect of adenosine receptor antagonist CGS-15943 and its vehicle in different tracheal segments of the same rat. As shown in Fig. 7B, the first concentration-response curve to fenoterol obtained in different tissues exhibited similar potencies. Pretreatment of tracheal rings with $2 \mu \mathrm{M}$ CGS-15943 induced a 2 -fold leftward shift of the second concentration-response curve to fenoterol without reduction in the maximal relaxation response (Fig. 7C). At $20 \mu \mathrm{M}$, CGS-15943 induced an 11-fold leftward shift $(P<0.05$; Student's $t$ test $)$ in the third fenoterol concentration-response curve without affecting the maximal relaxation (Fig. 7D). The values of $\mathrm{pEC}_{50}$ in response to fenoterol obtained in tracheas treated with CGS-15943 or vehicle are shown in Table 2.

\section{Discussion}

The extracellular cAMP-adenosine pathway has been described in several mammalian tissues, functioning as an extracellular feedback mechanism triggered in response to changes in intracellular cAMP levels (Jackson and Raghvendra, 2004; Godinho et al., 2015). Although the cAMP efflux from isolated perfused rat lung has been mentioned by Barnard et al. (1994) and recently described in human airway epithelial cells (Huff et al., 2017), its biologic function in the airway smooth muscle has never been experimentally addressed.

The current study provides reliable evidence for a functional extracellular cAMP-adenosine pathway in airway smooth muscle. First, the long-acting $\beta_{2}$-adrenoceptor agonist formoterol, used as bronchodilator for the management of persistent asthma symptoms, evoked a time-dependent efflux of cAMP from isolate tracheal rings, which was mimicked by the shortacting $\beta_{2}$ agonist fenoterol (Fig. 1). These results show that in tracheal smooth muscle the $\beta_{2}$-adrenoceptor-induced increase
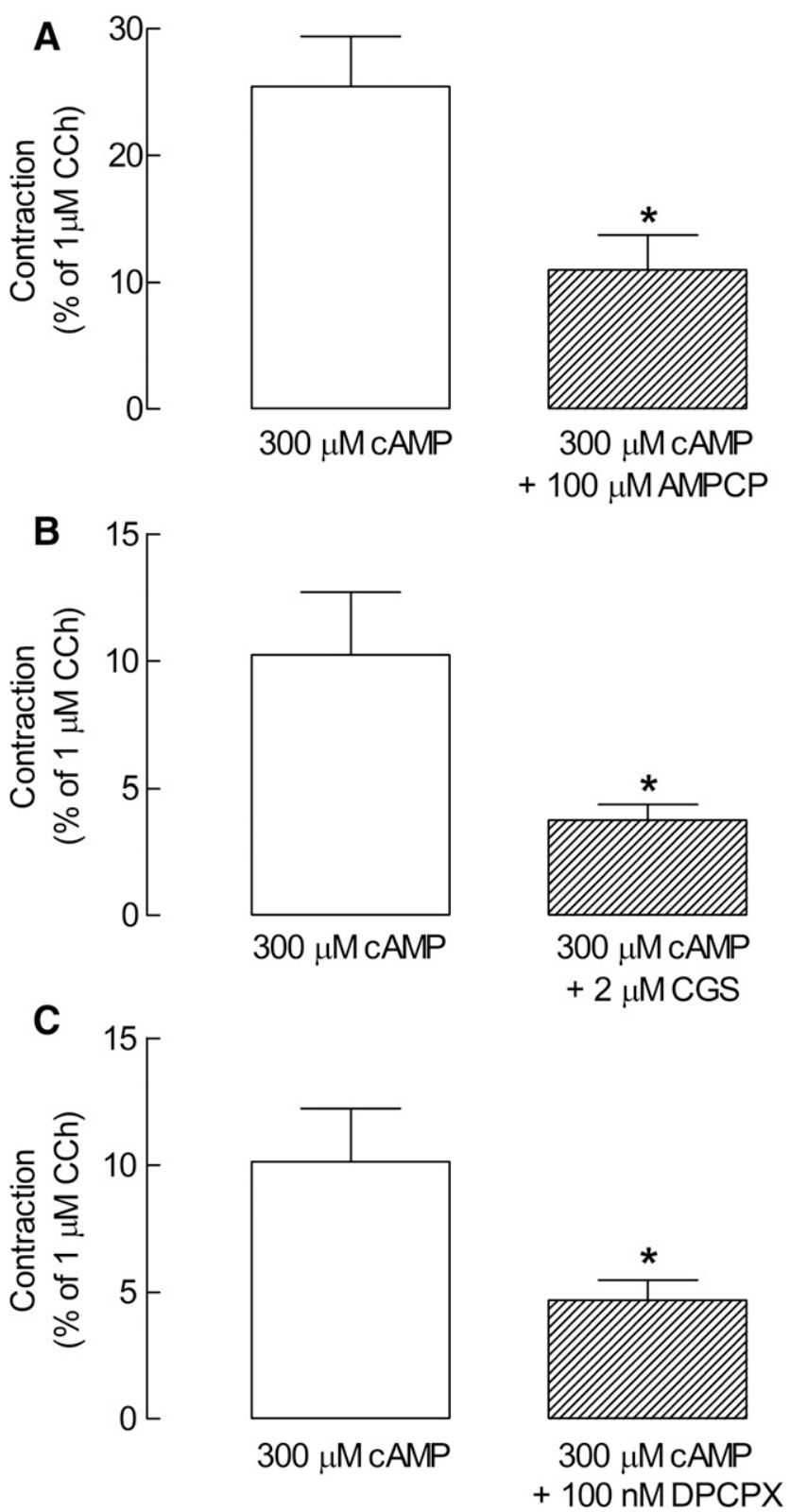

Fig. 5. Inhibition of either ecto-5'-nucleotidase or $A_{1}$ adenosine receptors reduces the cAMP-induced contractile response in rat tracheal rings precontracted with $\mathrm{CCh} \mathrm{EC}_{30}$. Isolated rat tracheas were incubated with AMPCP, a selective ecto-5' -nucleotidase inhibitor $(n=6)(\mathrm{A})$; CGS-15943, a nonselective adenosine receptor antagonist $(n=5)(\mathrm{B})$; or DPCPX, a selective $\mathrm{A}_{1}$ adenosine receptor antagonist $(n=7)(\mathrm{C})$ for 60 minutes, precontracted with $\mathrm{CCh}_{\mathrm{EC}}$ and the contractile response induced by cAMP was observed. Data are presented as mean \pm S.E.M. *Significantly different from $300 \mu \mathrm{M}$ cAMP $(P<0.05$; Student's $t$ test $)$.

in intracellular cAMP formation is followed by the efflux of the cyclic nucleotide to the extracellular space. Interestingly, the exogenous cAMP was able to induce airway smooth muscle contraction (Fig. 2A), likely through an extracellular mechanism, since the cell membrane is impermeable to cAMP (Robison et al., 1965). Considering the wet weight of tracheal tissue used in the present study $(26-28 \mathrm{mg})$, the cAMP released in $2.5 \mathrm{ml}$ of medium $(\sim 40-130 \mathrm{nM})$ after $\beta_{2}$-adrenoceptor stimulation and the extracellular fluid volume of rat trachea ( 1 ml/g dry tissue weight) (Woie and Reed, 1997), the cAMP released by the tracheal preparation 

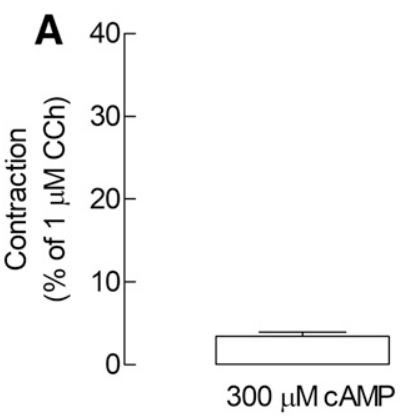

C

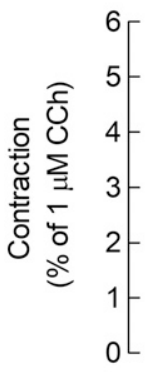

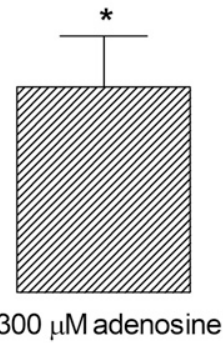

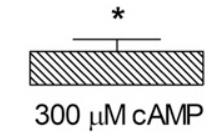

$+100 \mu \mathrm{M}$ AMPCP
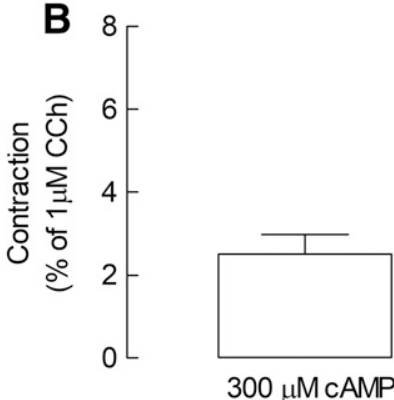

D
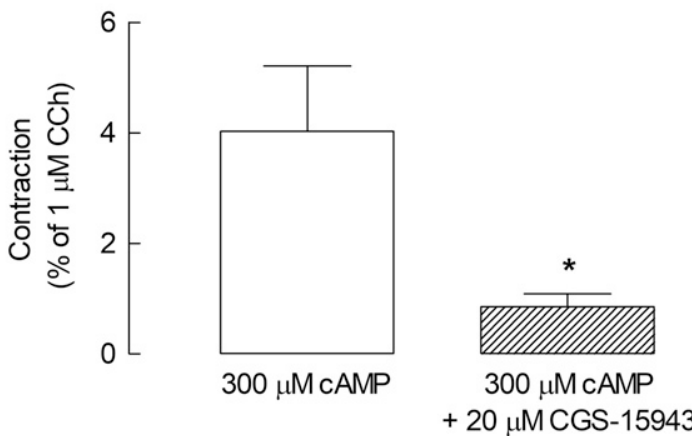

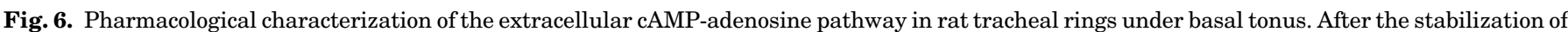

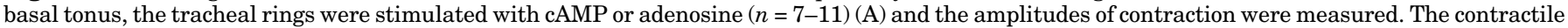

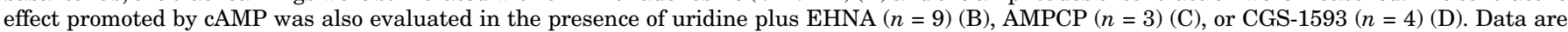
presented as the mean \pm S.E.M. *Significantly different from $300 \mu \mathrm{M}$ cAMP $(P<0.05$; Student's $t$ test $)$.

(Fig. 1B) could reach micromolar extracellular levels, which is the concentration required to induce muscle contraction (Fig. 2A).

Actually, the opposite effect of the membrane-permeable cAMP analog 8-Br-cAMP (Fig. 2B) and the significant reduction of cAMP-induced contraction observed in tracheal segments pretreated with the ecto-5'-nucleotidase inhibitor AMPCP (Fig. 5A; Fig. 6C) support an extracellular site of action of exogenous cAMP. The required involvement of ecto-5' - nucleotidase also indicates that the effect of cAMP on tracheal contractility depends on the extracellular cyclic nucleotide degradation into adenosine. Besides, whereas cAMP-induced contraction has been inhibited by nonselective (CGS-15943) and $\mathrm{A}_{1}$-selective (DPCPX) adenosine receptor antagonists (Fig. 5, B and C; Fig. 6D), it was oppositely affected by adenosine deaminase and adenosine uptake cocktail inhibitors (Fig. 4, E-G; Fig. $6 \mathrm{~B})$, showing that the effect of exogenous cAMP on tracheal contractility involves the activation of $\mathrm{A}_{1}$ adenosine receptors through its metabolite adenosine, as outlined in Fig. 8.

Our results also show that the contracting effect of extracellular cAMP is intensified in tracheal muscle precontracted with the cholinergic agonist $\mathrm{CCh}$ (Fig. 3), indicating a synergistic effect of cAMP/adenosine and $\mathrm{CCh}$ on the airway smooth muscle contraction. Essentially, these synergistic effects are consistent with the net increase in the intracellular $\mathrm{Ca}^{2+}$ induced by both $\mathrm{CCh}$, via activation of smooth muscle muscarinic $\mathrm{m} 3$ receptors/Gq protein (Wang and Kotlikoff, 1997; Billington and Penn, 2002), and adenosine, via $\mathrm{A}_{1}$ adenosine receptors/inhibitory $\mathrm{G}$ protein (Gerwins and Fredholm, 1992; Abebe and Mustafa, 1998).
Increasing evidence suggest that adenosine may be an important mediator of bronchial asthma since its levels are elevated in the bronchoalveolar lavage fluid of asthma patients (Driver et al., 1993). Using ragweed-sensitized and challenged mice as an allergic animal model, Fan and Mustafa (2002) showed that the inhalation of adenosine causes a doserelated bronchoconstriction, which was associated with enhanced influx of inflammatory cells into the bronchoalveolar lavage fluid. In addition, Yip et al. (2011) showed an inhibitory effect of $\mathrm{A}_{1}$ receptor antagonists on human mast cell activation. Adenosine also induces histamine release from human bronchoalveolar lavage mast cells (Forsythe et al., 1999). Furthermore, it is well known that at least part of the bronchodilator and anti-inflammatory effects of theophylline has been linked to adenosine receptor inhibition (Fredholm and Persson, 1982; Cheng et al., 2017). Actually, our results showed that the inhibition of adenosine receptors with CGS-15943 shifted to the left the relaxing curve of fenoterol (Fig. 7, C and D). The ability of the adenosine receptor antagonist to potentiate the relaxing effect of fenoterol effect suggests that combining a $\beta_{2}$ receptor agonist with a selective $A_{1}$ receptor blocker might provide better clinical control of lung diseases (asthma and chronic obstructive pulmonary disease). Therefore, taking into account the efflux of cAMP from tracheal cells and its extracellular degradation into adenosine, it is reasonable to suppose that the extracellular cAMP-adenosine pathway may influence airway function in diseases such as asthma. In fact, the existence of the extracellular cAMPadenosine pathway in tracheal smooth muscle may influence 

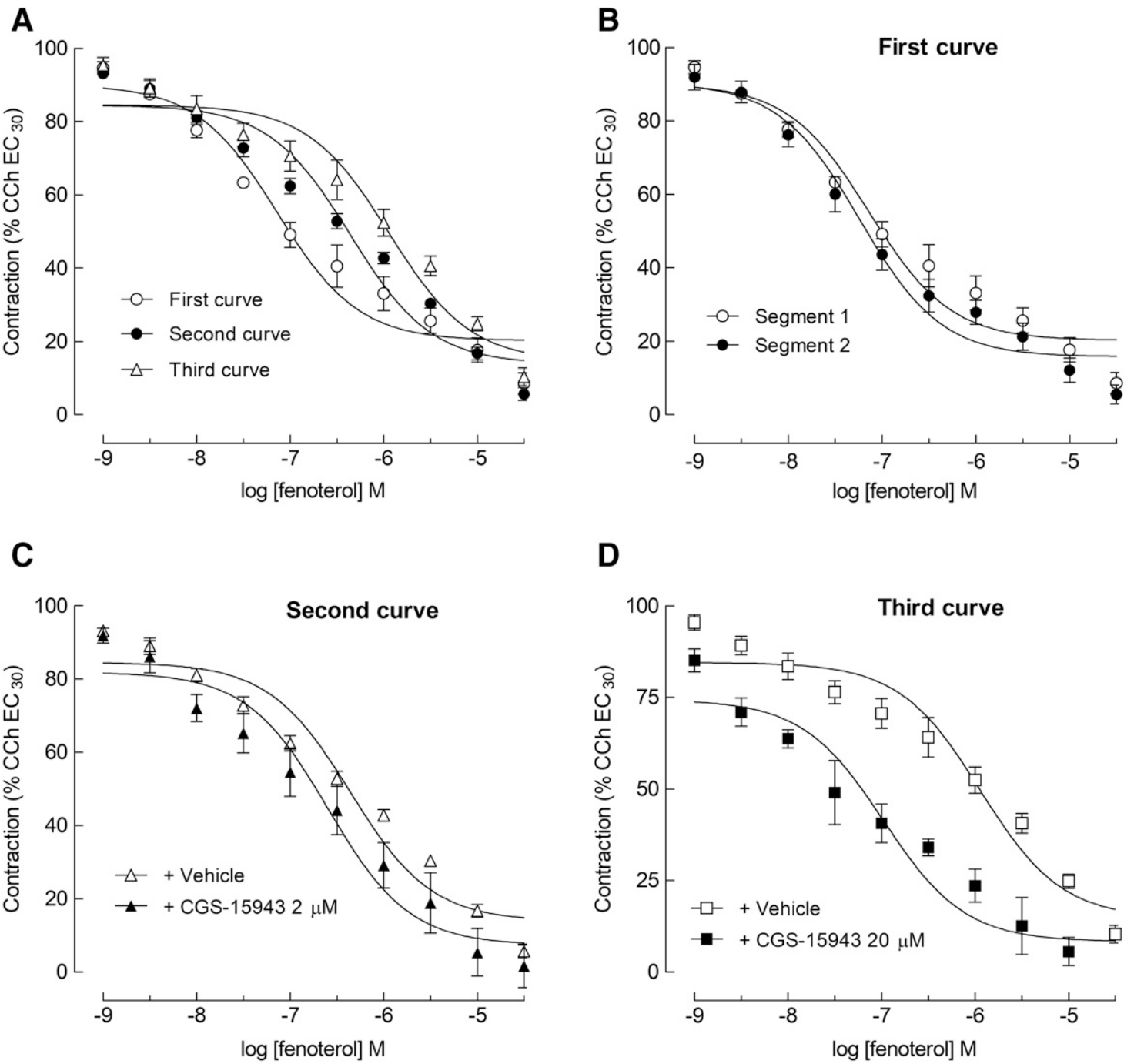

Fig. 7. Adenosine receptor antagonist potentiates the fenoterol-induced relaxation response in rat tracheal rings precontracted with $\mathrm{CCh}_{\mathrm{EC}} \mathrm{B}_{30}$. $(\mathrm{A})$ Three cumulative concentration-response curves to fenoterol were constructed at 60 -minute intervals $(n=4)$. (B) Control cumulative concentrationresponse curves to fenoterol from different tissues $(n=4-5)$. Isolated rat tracheas were incubated with vehicle (DMSO $0.2 \%)$ or CGS-15943 $2 \mu \mathrm{M}(n=4$ to

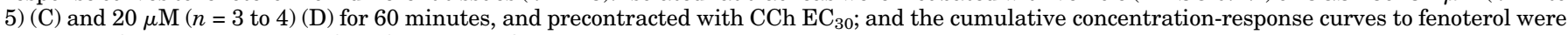
constructed. Data are presented as the mean \pm S.E.M.

the bronchodilator effects of $\beta_{2}$ adrenoceptor agonists, which is under investigation in our laboratory in animal models of airway inflammatory and allergic diseases.
Taken together, our results show that $\beta_{2}$-adrenoceptor induces cAMP efflux from tracheal smooth muscle, which is consistent with previous observations showing that activation

TABLE 2

Values of $\mathrm{pEC}_{50}$ obtained for fenoterol in the absence and presence of CGS-15943 in rat tracheal rings precontracted with $\mathrm{CCh} \mathrm{EC}_{30}$

Three consecutive cumulative concentration-response curves for fenoterol were constructed using two tracheal preparations (segments 1 and 2) of the same rat (Fig. 7) and analyzed through a nonlinear regression with GraphPad Prism 5 Software. Values are presented as mean \pm S.E.M.

\begin{tabular}{lccc}
\hline \multirow{2}{*}{ Treatment } & \multicolumn{3}{c}{$\mathrm{pEC}_{50}(n)$} \\
\cline { 2 - 4 } & First Curve & Second Curve & Third Curve \\
\hline Fenoterol (segment 1) & $7.03 \pm 0.18(4)$ & & \\
Fenoterol (segment 2) & $7.20 \pm 0.14(5)$ & & \\
+ Vehicle (segment 1) & & $6.36 \pm 0.10(4)$ & \\
+ CGS 2 $\mu$ M (segment 2) & & & $5.99 \pm 0.17(5)$ \\
+ Vehicle (segment 1) & & & $7.04 \pm 0.32^{*}(3)$ \\
+ CGS 20 $\mu$ M (segment 2) & & & \\
\hline
\end{tabular}

CGS, CGS-15943.

*Significantly different from vehicle (third curve) $(P<0.05$; Student's $t$ test). 


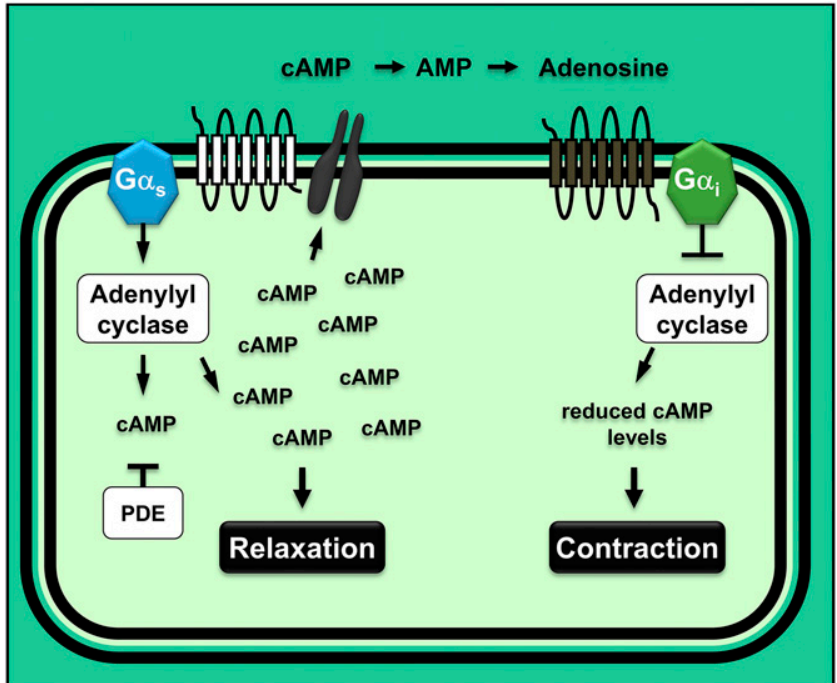

Fig. 8. Model of extracellular cAMP-adenosine signaling in airway smooth muscle. The activation of $\beta_{2}$-adrenoceptor induces a Gs-dependent activation of AC-dependent and cAMP-dependent relaxation of smooth muscle. Part of the intracellular cAMP is transported to the extracellular space, where it is sequentially converted to AMP and adenosine by the ectoenzymes. Then, the extracellular adenosine is able to activate $\mathrm{A}_{1}$ adenosine receptors inducing a secondary contraction of the smooth muscle.

of $\beta_{2}$-adrenoceptor by isoprenaline stimulates cAMP efflux in human airway epithelial cells (Geary et al., 1993) and rat lung perfusates (Barnard et al., 1994).

More importantly, to our knowledge our study is the first to report the presence of the extracellular cAMP-adenosine pathway in airway smooth muscle. Moreover, using pharmacological strategies we also show that the interstitial cAMP is metabolized by ectoenzymes into adenosine, which induces tracheal smooth muscle contraction by activating adenosine receptors. Considering the synergistic effects of extracellular cAMP and $\mathrm{CCh}$, which mimic the increased smooth muscle tone observed in asthma, the impact of cAMP efflux and the extracellular cAMP-adenosine pathway in the animal model of allergen-induced asthma is also under investigation by our group.

\section{Acknowledgments}

We thank Maria do Carmo Gonçalo and Wilma da Silva Cavalheiro Guerreiro Felisbino for excellent technical assistance. We also thank the Instituto de Farmacologia e Biologia Molecular (INFAR) MultiUser Laboratory at UNIFESP/Escola Paulista Medicina for the use of Flex Station 3 (Molecular Devices).

\section{Authorship Contributions}

Participated in research design: Pacini, Godinho.

Conducted experiments: Pacini, Sanders-Silveira.

Performed data analysis: Pacini, Godinho.

Wrote or contributed to the writing of the manuscript: Pacini, Godinho.

\section{References}

Abebe W and Mustafa SJ (1998) A1 adenosine receptor-mediated Ins(1,4,5)P3 generation in allergic rabbit airway smooth muscle. Am J Physiol 275:L990-L997.
Adriaensen D and Timmermans JP (2004) Purinergic signalling in the lung: important in asthma and COPD? Curr Opin Pharmacol 4:207-214.

Barnard JW, Seibert AF, Prasad VR, Smart DA, Strada SJ, Taylor AE and Thompson WJ (1994) Reversal of pulmonary capillary ischemia-reperfusion injury by rolipram, a cAMP phosphodiesterase inhibitor. J Appl Physiol (1985) 77: 774-781.

Billington CK and Penn RB (2002) m3 muscarinic acetylcholine receptor regulation in the airway. Am J Respir Cell Mol Biol 26:269-272.

Cazzola M, Page CP, Calzetta L, and Matera MG (2012) Pharmacology and therapeutics of bronchodilators. Pharmacol Rev 64:450-504.

Cheng D, Ren J, and Jackson EK (2010) Multidrug resistance protein 4 mediates cAMP efflux from rat preglomerular vascular smooth muscle cells. Clin Exp Pharmacol Physiol 37:205-207.

Cheng RKY, Segala E, Robertson N, Deflorian F, Doré AS, Errey JC, Fiez-Vandal C, Marshall FH, and Cooke RM (2017) Structures of human $\mathrm{A}_{1}$ and $\mathrm{A}_{2 \mathrm{~A}}$ adenosine receptors with xanthines reveal determinants of selectivity. Structure 25: 1275-1285.e4.

Chiavegatti T, Costa VL, Jr, Araújo MS, and Godinho RO (2008) Skeletal muscle expresses the extracellular cyclic AMP-adenosine pathway. $\mathrm{Br} J$ Pharmacol 153: 1331-1340.

de Lima WT and da Silva ZL (1998) Contractile responses of proximal and distal trachea segments isolated from rats subjected to immunological stimulation: role of connective tissue mast cells. Gen Pharmacol 30:689-695.

Driver AG, Kukoly CA, Ali S, and Mustafa SJ (1993) Adenosine in bronchoalveolar lavage fluid in asthma. Am Rev Respir Dis 148:91-97.

Duarte T, Menezes-Rodrigues FS, and Godinho RO (2012) Contribution of the extracellular cAMP-adenosine pathway to dual coupling of $\beta 2$-adrenoceptors to Gs and Gi proteins in mouse skeletal muscle. J Pharmacol Exp Ther 341:820-828.

Fan M and Mustafa SJ (2002) Adenosine-mediated bronchoconstriction and lung inflammation in an allergic mouse model. Pulm Pharmacol Ther 15:147-155.

Forsythe P, McGarvey LP, Heaney LG, MacMahon J, and Ennis M (1999) Adenosine induces histamine release from human bronchoalveolar lavage mast cells. Clin Sci (Lond) 96:349-355.

Fredholm BB, IJzerman AP, Jacobson KA, Linden J, and Müller CE (2011) International Union of Basic and Clinical Pharmacology. LXXXI. Nomenclature and classification of adenosine receptors-an update. Pharmacol Rev 63:1-34.

Fredholm BB and Persson CG (1982) Xanthine derivatives as adenosine receptor antagonists. Eur J Pharmacol 81:673-676.

Geary CA, Goy MF, and Boucher RC (1993) Synthesis and vectorial export of cGMP in airway epithelium: expression of soluble and CNP-specific guanylate cyclases. Am J Physiol 265:L598-L605.

Gerwins P and Fredholm BB (1992) ATP and its metabolite adenosine act synergistically to mobilize intracellular calcium via the formation of inositol 1,4,5-trisphosphate in a smooth muscle cell line. J Biol Chem 267:16081-16087.

Godinho RO and Costa VL, Jr (2003) Regulation of intracellular cyclic AMP in skeletal muscle cells involves the efflux of cyclic nucleotide to the extracellular compartment. Br J Pharmacol 138:995-1003.

Godinho RO, Duarte T, and Pacini ES (2015) New perspectives in signaling mediated by receptors coupled to stimulatory $G$ protein: the emerging significance of cAMP efflux and extracellular cAMP-adenosine pathway. Front Pharmacol 6:58.

Huff RD, Rider CF, Yan D, Newton R, Giembycz MA, Carlsten C, and Hirota JA (2017) Inhibition of ABCC4 potentiates combination beta agonist and glucocorticoid responses in human airway epithelial cells. J Allergy Clin Immunol 141: 1127-1130.e5.

Huszár E, Vass G, Vizi E, Csoma Z, Barát E, Molnár Világos G, Herjavecz I, and Horváth I (2002) Adenosine in exhaled breath condensate in healthy volunteers and in patients with asthma. Eur Respir $J$ 20:1393-1398.

Jackson EK and Raghvendra DK (2004) The extracellular cyclic AMP-adenosine pathway in renal physiology. Annu Rev Physiol 66:571-599.

Mi Z and Jackson EK (1995) Metabolism of exogenous cyclic AMP to adenosine in the rat kidney. $J$ Pharmacol Exp Ther 273:728-733.

Robison GA, Butcher RW, Oye I, Morgan HE, and Sutherland EW (1965) The effect of epinephrine on adenosine $3^{\prime}, 5^{\prime}$-phosphate levels in the isolated perfused rat heart. Mol Pharmacol 1:168-177.

Sassi Y, Abi-Gerges A, Fauconnier J, Mougenot N, Reiken S, Haghighi K, Kranias EG, Marks AR, Lacampagne A, Engelhardt S, et al. (2012) Regulation of cAMP homeostasis by the efflux protein MRP4 in cardiac myocytes. FASEB $J \mathbf{2 6}$ : 1009-1017.

Wang YX and Kotlikoff MI (1997) Muscarinic signaling pathway for calcium release and calcium-activated chloride current in smooth muscle. Am J Physiol 273: C509-C519.

Wilson CN, Nadeem A, Spina D, Brown R, Page CP, and Mustafa SJ (2009) Adenosine receptors and asthma. Handb Exp Pharmacol 193:329-362.

Woie K and Reed RK (1997) Alloxan diabetes abolishes the increased negativity of interstitial fluid pressure in rat trachea induced by vagal nerve stimulation. Acta Physiol Scand 161:113-119.

Yip KH, Lau HY, and Wise H (2011) Reciprocal modulation of anti-IgE induced histamine release from human mast cells by $\mathrm{A}_{1}$ and $\mathrm{A}(2 \mathrm{~B})$ adenosine receptors. Br J Pharmacol 164 (2b):807-819.

Address correspondence to: Dr. Rosely O. Godinho, Department of Pharmacology, EPM/UNIFESP, Rua Três de Maio 100, São Paulo, São Paulo 04044-020, Brazil. E-mail: godinho@unifesp.br 